\title{
Architectures for Microgrids Interconnection
}

\author{
Fabián Díaz \\ Faculty of Engineering \\ University of Talca \\ Curicó, Chile \\ fadiaz11@alumnos.utalca.cl
}

\author{
Marco Rivera \\ Faculty of Engineering \\ University of Talca \\ Curicó, Chile \\ marcoriv@utalca.cl
}

\author{
Héctor Chávez \\ Faculty of Engineering \\ University of Santiago) \\ Santiago, Chile \\ hector.chavez@usach.cl
}

\author{
Patrick Wheeler \\ Dept. of Electrical and Electronic Engineering \\ University of Nottingham \\ Nottingham, England \\ patrick.wheeler@nottingham.ac.uk
}

\begin{abstract}
Progress requires greater global energy interconnection. This paper presents an overview of the topologies and control techniques applied to microgrids, by means of an updated bibliographic research and the most relevant articles on the use of power electronics in microgrids interconnection. The topologies and control techniques investigated in this paper expose a reality that leads to commercial solutions applied to microgrids, giving new tools to the energy market.
\end{abstract}

Index Terms-Microgrids, Interconnection, Topologies, Power Converters, Control, HVDC.

\section{INTRODUCTION}

$\mathbf{T}$ HE concept of microgrids is conceived within the framework of developing a more flexible and reliable energy solution. Currently, microgrids are implemented in areas of difficult access to the supply of electricity, usually in rural areas [1]. The microgrids are made up of a series of generating equipment from different sources, mostly renewable. They have various components of power electronics to interconnect between the power grid and the generation systems [2]. In addition, control techniques that allow synchronization and monitoring of currents are added to the microgrids. To facilitate the interconnection, bidirectional topologies have been developed so, together with control techniques make possible the interconnection between AC microgrids and DC microgrids or vice versa [3]. In the area of research, in recent years, topologies have been improved in order to facilitate the interconnection of microgrids, generating new concepts and ideas, with new and more efficient control techniques [4]. It is necessary to document these advances by an overview of the technologies within the distributed generation, similar works present a compilation of advances in topologies and control techniques of DC-DC converters for the interconnection of microgrids, especially for the production of energy from of photovoltaic panels [5]. This paper describes the existing power electronics topologies together with the control techniques used for the interconnection of microgrids. It provides a relevant novelty from similar ones available in scientific journals, since the objective of this paper is to present an overview of the advances in power electronics and control techniques applied to the interconnection of microgrids.

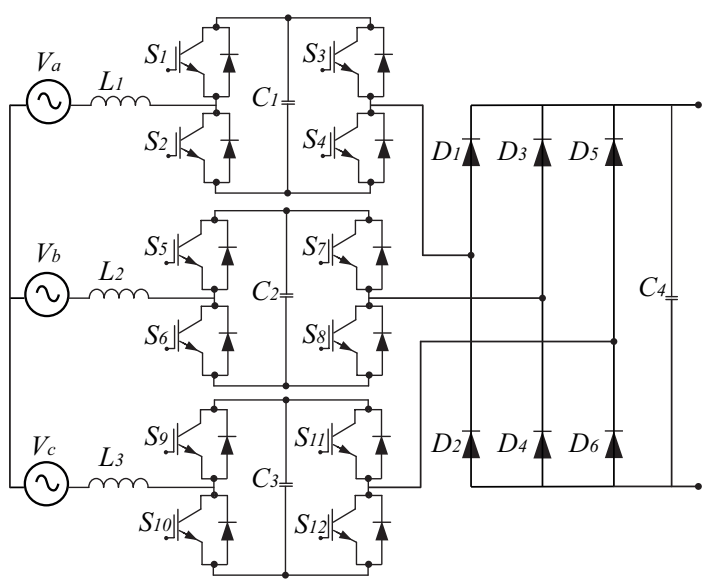

Fig. 1. Voltage source PFC for harmonic compensation [11].

\section{Current Topologies in Power Electronics}

Among the current topologies are the AC-DC, DC-DC, DC$\mathrm{AC}$ and $\mathrm{AC}-\mathrm{AC}$ conversion [5]. By combining these topologies it is possible to find hybrid configurations that allow various specific applications related to power electronics [6].

\section{A. AC-DC Converters}

Usually the large-scale electric power generation is of the alternate type, being generated by $\mathrm{AC}$ alternators. This generated energy feeds loads that require an alternate $(\mathrm{AC})$ or continuous (DC) supply, being necessary the AC-DC conversion using power converters [7]. These converters can be used to operate in low, medium and high voltage applications [8]. The diode bridge or rectifier bridge is the most typical configuration used in current rectification, however, this generates a considerable harmonic distortion (THD) [9], so more efficient configurations have been chosen, where the diodes have been replaced by power factor correction (PFC) circuits, with a THD that reaches the IEEE standard of 5\% allowed [10]. In Fig. 1 the voltage source PFC topology for harmonic compensation is observed.

\section{B. DC-AC Converters}

DC-AC converters or inverters allow generating outputs of magnitude, phase and frequency determined from a DC source. The inverters are used in a wide variety of applications, from 


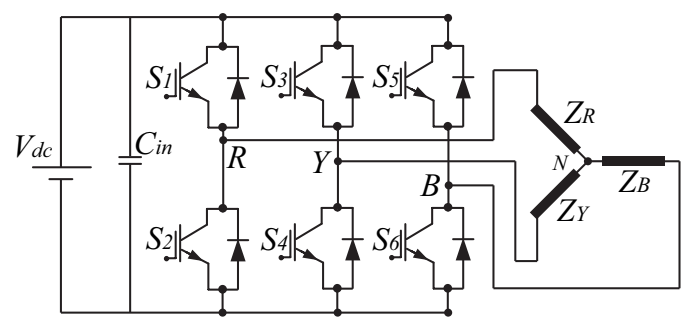

Fig. 2. Three-phase voltage source inverter VSI.

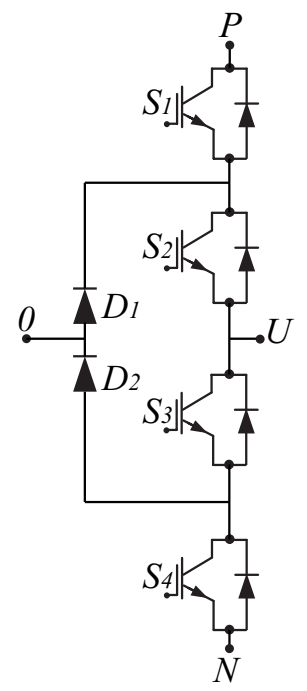

(a)

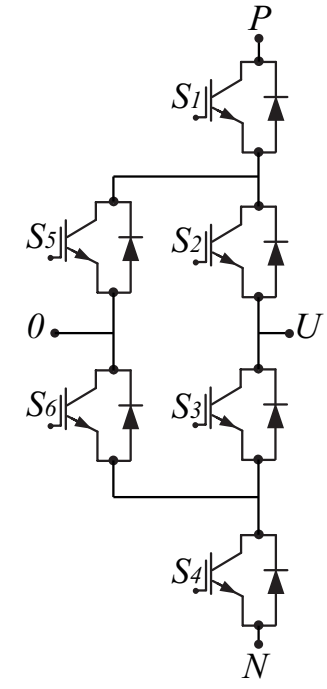

(b)
Fig. 3. NPC inverter topologies (a) 3L DCNPC (b) 3L ANPC [11].

the interconnection of photovoltaic solar panels, accumulators or batteries to industrial applications to control high power [12]. Among the topologies used in the market are VSI (Voltage Source Inverter), CSI (Current Source Inverter) and inverters based on $\mathrm{H}$ bridge topologies [13].

\section{DC-DC Converters}

DC-DC converters receive a DC voltage input to deliver a DC output of higher or lower voltage level, reversing their polarity for some topologies. In microgrids, these converters are widely used as an interface between the power grid and storage systems or electric vehicles. Within the market there are two types of these converters, the isolated and non-isolated [14]. DC-DC converters without isolation are characterized by electromagnetic storage which makes them large and heavy. These converters can be classified as buck converters, boost and buck-boost [11].

\section{1) DC-DC Converters without Galvanic Isolation:}

a) Buck Converter: the buck converter is a voltage reducing converter, which by a DC supply obtains a DC output with a lower voltage level [14]. In microgrids buck converters are used in battery chargers circuits, these allow a correct balance of the cell's voltage levels. b) Boost Converter: the boost converter is characterized by being supplied by a DC voltage, obtaining a DC output with a higher voltage level [15]. Boost converters are used to connect lower voltage DC microgrids (between $12 \mathrm{v}$ and $24 \mathrm{v}$ ) with a higher voltage microgrid $(380 \mathrm{v})$, generally installed in rural areas [16].

c) Buck-Boost Converter: the buck-boost converter can act as a reducer and a voltage booster. This converter acts as a buck converter or a boost converter depending on the duty cycle of the switching transistor. This converter can only work in continuous mode [17]. These types of power converters are used as an interface between photovoltaic generation systems or wind turbines with a DC microgrid [18].

d) Cuk Converter: the cuk converter is a voltage reducing converter and its output has an inverse polarity to the input. This converter has the ability to work in continuous or discontinuous mode [19]. In microgrids these converters are used to form hybrid topologies as discussed in [20].

e) SEPIC Converter: the SEPIC converter (single-ended primary inductor converter) is a reducing converter with a noninverting output. SEPIC converters are also used as isolated DC-DC converters by serially connecting two of these converters. [21].

f) Zeta Converter: the zeta converter can act as a reducer or as a voltage booster, in addition to having a non-inverting output. This converter is often referred to as double SEPIC [22].

2) DC-DC Converters with Galvanic Isolation:

a) Flyback Converter: the flyback converter is a DC-DC converter similar to the Buck-Boost converter in operation. It is suitable for low power applications, less than 100W [19].

b) Forward Converter: this converter can change the voltage level of its output depending on the number of turns of the transformer. It is suitable for medium power applications, between 200W and 500W [19].

c) Push-Pull Converter: the transformer of this converter has bidirectional excitation. It has a low noise level and a constant flow of current [23].

d) Half-Bridge Converter: the power supply of this converter can be divided through the implementation of capacitors, obtaining different levels of power. This topology allows a lower deterioration of the switch and is usually used in applications over 500W [24].

e) Full-Bridge Converter: this converter operates as a voltage reducing converter. It is used in high power applications, over $1 \mathrm{~kW}$ [25].

\section{AC-AC Converters}

Historically, AC-AC converters have been widely employed in industry, usually to control the rotational speed of $\mathrm{AC}$ motors. Today these converters are being used and studied for the interconnection between microgrids and power generation systems. These converters are capable of delivering an $\mathrm{AC}$ output with different amplitudes, phases or frequencies, as required by the load. Basically an AC-AC converter can be made up of a rectifier and an inverter linked by a DC-link, 


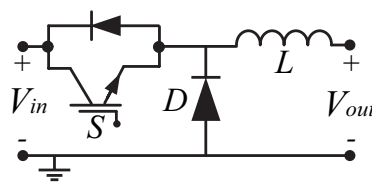

(a)

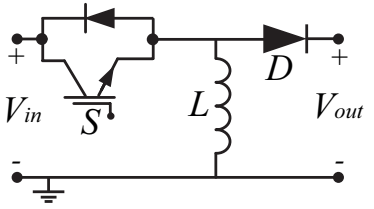

(c)

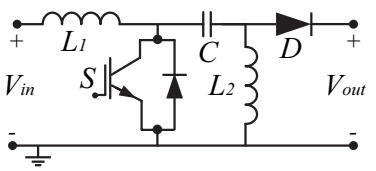

(e)

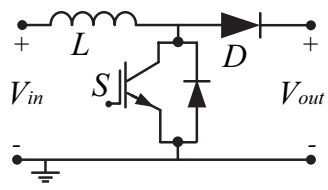

(b)

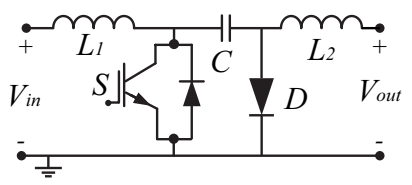

(d)

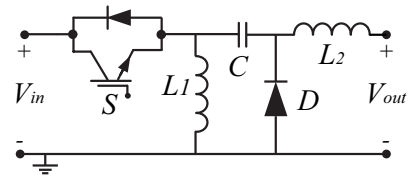

(f)
Fig. 4. DC-DC converter topologies without galvanic isolation (a) buck, (b) boost, (c) buck-boost, (d) cuk, (e) SEPIC, (f) zeta. [11].

however there are topologies that fulfill the same purpose without having a DC-link. Converters of this type are mainly divided into two types, cycloconverters and matrix converters.

1) Cycloconverters: cycloconverters are commonly known as frequency inverters, converting the $\mathrm{AC}$ power of a given frequency to an AC output of a desired frequency other than the power supply, without the need for a DC-link. Cycloconverters are widely ocuppied in the industry to perform a speed control in high power AC motors [26].

2) Matrix Converters: matrix converters are designed with a compact size, making use of bidirectional switches, obtaining at the output an AC signal with a unit power factor [27].

\section{E. Hybrid Converters}

The hybrid converters unlike the mentioned converters, by means of the application of a single conversion stage they achieve an AC and DC conversion, which allows to connect diverse loads within a hybrid network system. These converters are widely used in nanogrids architectures integrated in modern smart residential electrical power systems. Figure 8 shows a hybrid converter with AC and DC loads, this is composed of a boost converter and a VSI [28].

\section{Current Control Techniques Applied to POWER CONVERTERS}

Control techniques in power converters have evolved according to the needs they require, in relation to generating an input or output of greater efficiency and reliability. Its function is to regulate the main variables, such as voltage, current or power, in order to obtain a maximum performance [29]. The development of the control theory has allowed to establish varied control techniques for the interconnection of microgrids with generation systems, such as conventional ones, where techniques such as hysteresis band control, linear control, sliding mode control (SMC) and predictive. As well as intelligent control techniques based on the development of the field of artificial intelligence, such as control by artificial neural networks (ANN), fuzzy logic and ANFIS (adaptive neuro fuzzy interface system) [30].

\section{A. Hysteresis Band Control}

The hysteresis band control is a relatively simple nonlinear type control and considers a hysteresis bandwidth given by the error. This control technique can also be implemented as current control or direct power control (DPC). The hysteresis bandwidth that characterizes this control technique entails the need to implement large filters, with a high monetary cost, due to the considerable harmonic content that is generated, product of the variable switching that occurs when having that width of band [31]. In microgrids, it is used as a current control, in order to adjust the output current to the grid, ensuring the correct transmission of energy [32].

\section{B. Lineal Control}

For linear controllers in the interconnection of microgrids, its common the use of PI and PR controllers. These are mainly based on generating closed loop stability in the frequency domain. The type of linear control most used is the integral proportional (PI), however, this type of control presents problems with disturbances, so as an alternative a proportional resonant control (PR) is implemented, however, this presents problems due to the complexity of its implementation and design difficulty to reject multiple harmonics.

\section{Sliding Mode Control (SMC)}

Sliding mode control (SMC) is a non-linear control method that alters the dynamics of a non-linear system by applying a discontinuous control signal that forces the system to slide along a cross section of the normal behavior of the system. The SMC control is characterized by presenting a variable switching frequency, error in permanent mode and low dynamics in load variations. This type of control is used in microgrids to keep the DC-link voltage level stable and maintain a sinusoidal current from an $\mathrm{AC}$ voltage input in the presence of significant variations in load power [33].

\section{Predictive Control}

There are different types of predictive control, however, its common/key characteristic is the use of a system model to calculate predictions of the behavior of the variables to be controlled, together with an optimization criterion that allows to act in the most efficient way [34].

The deadbeat predictive control uses a system model to calculate the voltage that cancels the error over time of a sample, thereby applying the voltage using a modulator. However, this type of control is sensitive to possible variations in its parameters, which requires additional configurations to compensate for this sensitivity. The model-based predictive control (MPC) is the most commonly used to predict and optimize the output of a converter based on a predefined optimization criterion. This type of control includes optimal 


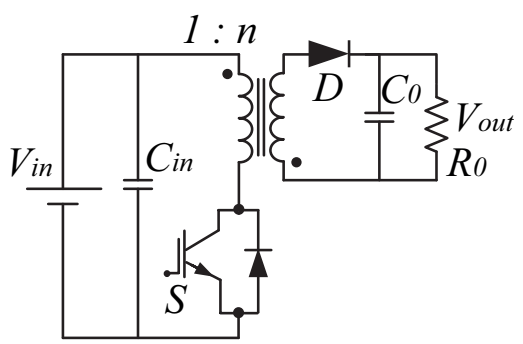

(a)

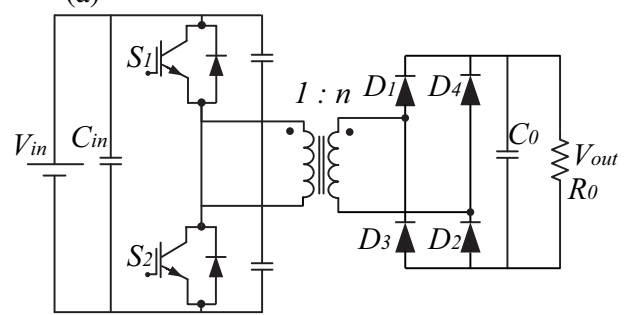

(d)

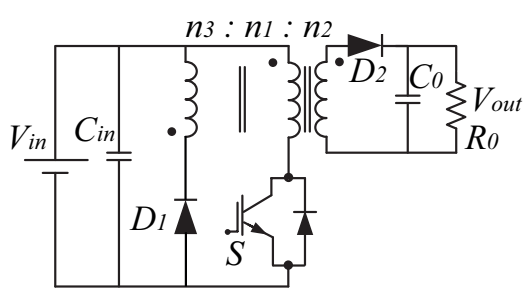

(b)

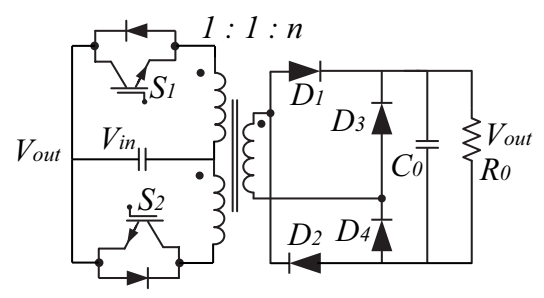

(c)

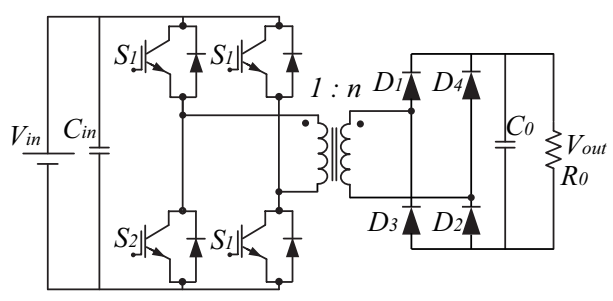

(e)

Fig. 5. DC-DC converter topologies with galvanic isolation (a) flyback, (b) forward, (c) push-pull, (d) half-bridge, (e) full-bridge [11].

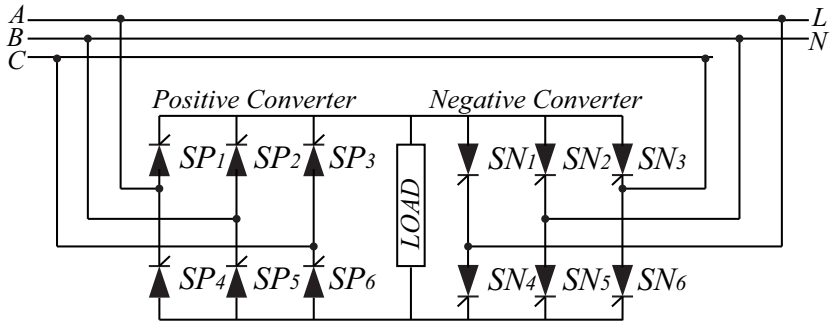

Fig. 6. Monofasic cycloconverter [11].

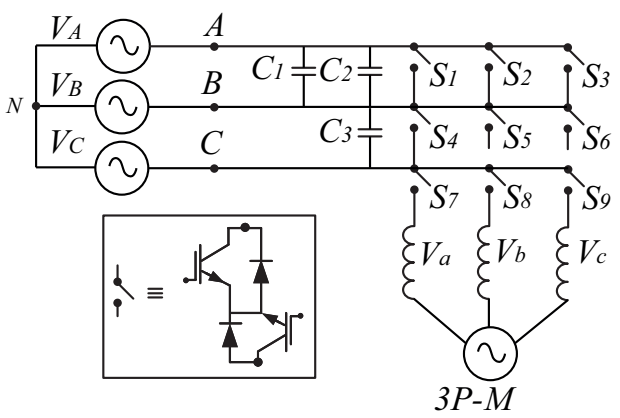

Fig. 7. Matrix converter $3 \times 3$ [11].

control strategies, dead time process control, multivariable process control, etc. This makes the MPC one of the most complete control techniques. Among the advantages of the MPC are:

- The delays produced in the system response can be compensated.

- The controller has a simple level of implementation.

- It allows modifications or extensions to increase its efficiency within specific applications.

However, the MPC control has some disadvantages, such

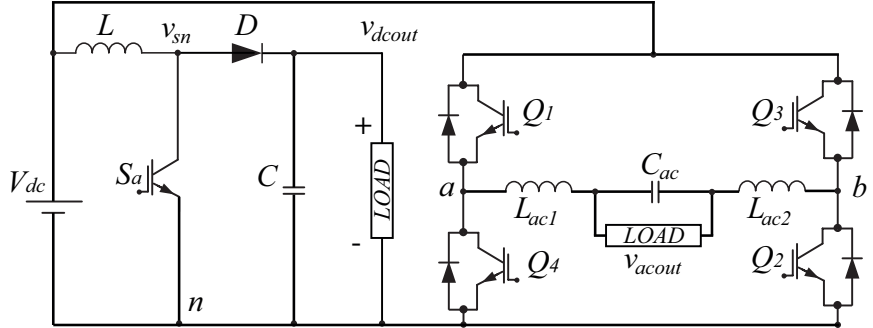

Fig. 8. Hybrid converter composed of a boost converter and a VSI [28].

as the density of calculations that must be performed in comparison to another control techniques, the correct representation of the dynamic model of the system directly influences the efficiency of the controller, in addition to whether the parameters of the system are variable over time, an parameter estimation algorithm should be considered.

\section{E. Control Based on Artificial Intelligence}

With the development of the areas of computer engineering and control theory, more sophisticated control techniques have been implemented, which has given rise to intelligent controllers. Within the control techniques based on artificial intelligence, diffuse logic control stands out, this is based on the knowledge of the system by the designer, this being the parameter that defines the efficiency of the controller, this is the basis of the techniques of this type of controllers, where the degree of knowledge varies and how this can be generated through the training of artificial intelligence. These types of control are used within the microgrids to intelligently control the active and reactive power parameters that are injected into the microgrid. 


\section{ACtual Examples for the InTERCONNECTION OF MICROGRIDS}

AC transmission is widely used in the implementation of conventional microgrids and electrical networks for high power distribution or transmission, while DC transmission is used to interconnect extremely long distances, for example, intercontinental submarine cables. This is due to the fact that in large lengths there is a smaller amount of losses per DC transmission than in AC. However, in order to take advantage of the low losses of DC transmission over large areas of land, high-voltage direct current (HVDC) electrical transmission systems have been developed [35]. The main characteristics of HVDC systems are presented below, together with their participation in the energy market together with power electronics.

\section{A. HVDC Systems}

Electric networks and microgrids work in the AC domain, due to their robustness in transmission systems at various voltage levels. HVDC systems allow the interconnection of non-synchronized AC systems, this through an HVDC link, since this link has the ability to control the flow of current without relying on the synchronization of the networks to be interconnected. The interconnection is produced by performing the AC-DC transformation of the AC network that you want to interconnect, it goes through an HVDC link stage with a DC-DC transformation, to finally synchronize with the other $\mathrm{AC}$ network participating in the interconnection by a DC-AC transformation.

The interconnection in electrical systems has allowed the energy exchange in European countries since the 1950s, with HVDC system installations implemented in the Soviet Union between the cities of Moscow and Kashira [36]. HVDC links allow the energy generated in large power generation centers to be transported to remote locations that often represent difficult access for conventional AC transmission networks, for example, in Canada, HVDC lines transport energy produced by hydroelectric sources to stations DC-AC conversion for use in the southern network of the province of Manitoba [37].

In 2016, the multinational corporation Grupo ABB reached an agreement with the authorities of China, to build an HVDC link with a voltage of $1100 \mathrm{kV}$, with a length of $3,000 \mathrm{~km}$ and $12 \mathrm{GW}$ of power. This agreement has established a new world record as the link with the greatest electrical potential, the greatest distance and the highest transmission capacity, currently this high-power link is called the ultra-high voltage direct current link (UHVDC). [38].

\section{B. HVDC Converters}

To perform the aforementioned conversions for interconnection of microgrids and electrical networks, in high voltage systems it is necessary to implement topologies that allow maximum use of the characteristics required by the systems. The HVDC converters currently used for interconnection of microgrids are two, the line-switched converters and the voltage source converters [6].
The line-commutated converter (LCC), is characterized by having no control over the direction of the flow of current, however, this type of topology is widely used in HVDC systems. LCC converters are used in projects that require very high capacity and very high energy efficiency. Using topologies such as the rectifier bridge of six and twelve pulses, using thyristors instead of diodes. The voltage source converter (VSC) is mainly used in interconnection of lower voltage AC systems, for example, for the implementation of HVDC link in large-scale wind fields to the power grid. This converter can have a multilevel topology to achieve various levels of voltages and a higher wave quality at the output.

During the last years VSC topologies with harmonic compensation have been developed to reduce the amount of switching losses and have a high harmonic performance in their multilevel configuration [39]. Currently, the Japanese company Toshiba has products within its technical services for transmission and electrical distribution for HVDC systems. Toshiba is a brand present in all HVDC projects in their country, achieving position as a leader in distribution of HVDC solutions. The Japanese brand has multilevel VSC converters in the HVDC Hokkaido-Honshu project, which includes a HVDC link of $300 \mathrm{MW}, 250 \mathrm{kV}$ DC and $1200 \mathrm{~A}$. Together with LCC converters in the project that includes the interconnection of the Montenegrin line to a Italian line in construction, interconnecting in this way two electrical systems of different frequency of $500 \mathrm{kV}$ [40].

\section{CONClusion}

In this work, a review of the current technological tools used for interconnection of microgrids has been presented, exposing the topologies of power electronics and the main control techniques used in microgrids, giving a global vision on the current uses of these tools and their market share. At present, the power electronics topologies have allowed the development of new high-performance commercial solutions and the evolution of the electrical system worldwide in the process of achieving a system of greater interconnection, opening roads to the energy production market.

\section{ACKNOWLEDGMENT}

The authors appreciate the financial support of the FONDECYT Regular Project 1160690, and the thematic task on Energy-CUECH Research Network.

\section{REFERENCES}

[1] S. Shankar, A. C. Sridhar, A. Gopikanna, V. K. Shankar, and V. Vijayaraghavan, "Efficiency-cost design optimization for a stand-alone rural microgrid," in 2019 IEEE Power and Energy Conference at Illinois (PECI), Feb 2019, pp. 1-6.

[2] Z. Guoping, W. Weijun, and M. Longbo, "An overview of microgrid planning and design method," in 2018 IEEE 3rd Advanced Information Technology, Electronic and Automation Control Conference (IAEAC), Oct 2018, pp. 326-329.

[3] J. Jiao, R. Meng, Z. Guan, C. Ren, L. Wang, and B. Zhang, "Gridconnected control strategy for bidirectional ac-dc interlinking converter in ac-dc hybrid microgrid," in 2019 IEEE 10th International Symposium on Power Electronics for Distributed Generation Systems (PEDG), June 2019, pp. 341-345. 
[4] Y. Han, K. Zhang, H. Li, E. A. A. Coelho, and J. M. Guerrero, "Masbased distributed coordinated control and optimization in microgrid and microgrid clusters: A comprehensive overview," IEEE Transactions on Power Electronics, vol. 33, no. 8, pp. 6488-6508, Aug 2018.

[5] M. Hossain, N. Rahim, and J. a/l Selvaraj, "Recent progress and development on power dc-dc converter topology, control, design and applications: A review," Renewable and Sustainable Energy Reviews, vol. 81, pp. 205 - 230, 2018. [Online]. Available: http://www.sciencedirect.com/science/article/pii/S1364032117310857

[6] D. Jovcic and L. Zhang, "Lcl dc/dc converter for dc grids," IEEE Transactions on Power Delivery, vol. 28, no. 4, pp. 2071-2079, Oct 2013.

[7] N. Muñoz-Galeano, J. B. Cano-Quintero, and J. M. López-Lezama, "Control de un convertidor elevador de voltaje ac/dc utilizando balance de potencias," Información Tecnológica, vol. 27, pp. 03 - 10, 002016. [Online]. Available: https://scielo.conicyt.cl

[8] H. Wu, S. Wong, C. K. Tse, and Q. Chen, "Control and modulation of bidirectional single-phase ac-dc three-phase-leg spwm converters with active power decoupling and minimal storage capacitance," IEEE Transactions on Power Electronics, vol. 31, no. 6, pp. 4226-4240, June 2016.

[9] "Ieee recommended practice and requirements for harmonic control in electric power systems," IEEE Std 519-2014 (Revision of IEEE Std 5191992), pp. 1-29, June 2014.

[10] M. Alam, W. Eberle, D. S. Gautam, C. Botting, N. Dohmeier, and F. Musavi, "A hybrid resonant pulse-width modulation bridgeless ac-dc power factor correction converter," IEEE Transactions on Industry Applications, vol. 53, no. 2, pp. 1406-1415, March 2017.

[11] H. P. N. Siwakoti YP, Forouzesh M, "Control of power electronic converter and systems," Chapter 1: Power Electronics Converters, 2018.

[12] G. L. Niewiara LJ, Tarczewski T, "Application of DC/DC/AC dual voltagesource inverter for current harmonics reduction in PMSM drive." pp. 1-9, 2017.

[13] D. V. L. F. Samir Kouro, Jose Leon, "Grid-connected photovoltaic systems," IEEE Industrial Electronics Magazine, pp. 47 - 61, March 2015.

[14] F. Asadi and K. Eguchi, "Dynamics and control of dc-dc converters," Synthesis Lectures on Power Electronics, vol. 6, no. 1, pp. 1-241, 2018, cited By 2. [Online]. Available: https://www.scopus.com

[15] S. Sinha, Vinayak, A. Gullapalli, S. S. John, and S. Kundu, "Dc dc boost converter for thermoelectric energy harvesting," in 2018 International Conference on Current Trends towards Converging Technologies (ICCTCT), March 2018, pp. 1-4.

[16] C. D. M. Cheema, K. S. Shah, H. A. Khan, and N. A. Zaffar, "Design and analysis of isolated boost converter for microgrid applications," in IECON 2017 - 43rd Annual Conference of the IEEE Industrial Electronics Society, Oct 2017, pp. 2431-2436.

[17] S. N. Soheli, G. Sarowar, M. A. Hoque, and M. S. Hasan, "Design and analysis of a dc -dc buck boost converter to achieve high efficiency and low voltage gain by using buck boost topology into buck topology," in 2018 International Conference on Advancement in Electrical and Electronic Engineering (ICAEEE), Nov 2018, pp. 1-4.

[18] D. Zammit, C. Spiteri Staines, M. Apap, and A. Micallef, "Control of buck and boost converters for stand-alone dc microgrids," 082018.

[19] N. Mohan, T. M. Undeland, and W. P. Robbins, Power Electronics. Converters, Applications and Design, 3rd ed. John Wiley and Sons, Inc, 2003.

[20] K. Tseng and C. Huang, "High step-up high-efficiency interleaved converter with voltage multiplier module for renewable energy system," IEEE Transactions on Industrial Electronics, vol. 61, no. 3, pp. 13111319, March 2014.

[21] B. M. H. Jassim, "Sepic ac-dc converter for aircraft application," in MELECON 2014 - 2014 17th IEEE Mediterranean Electrotechnical Conference, April 2014, pp. 12-16.

[22] D. Murthy-Bellur and M. K. Kazimierczuk, "Isolated two-transistor zeta converter with reduced transistor voltage stress," IEEE Transactions on Circuits and Systems II: Express Briefs, vol. 58, no. 1, pp. 41-45, Jan 2011.

[23] K. Gopinathan and Mamatha I, "Pre-regulated push pull converter for hybrid energy systems," in 2015 International Conference on Technological Advancements in Power and Energy (TAP Energy), June 2015, pp. 121-126.

[24] J. Han, J. Kim, and G. Moon, "A high-efficiency asymmetrical halfbridge converter with integrated boost converter in secondary rectifier,"
IEEE Transactions on Power Electronics, vol. 32, no. 11, pp. 8237-8242, Nov 2017.

[25] W. Zhifu, W. Yupu, and R. Yinan, "Design of closed-loop control system for a bidirectional full bridge $\mathrm{dc} / \mathrm{dc}$ converter," Applied Energy, vol. 194, pp. 617 - 625, 2017. [Online]. Available: http://www.sciencedirect.com/science/article/pii/S0306261916317445

[26] M. Basirifar, "“'a comparative study of circulating free and circulating current cycloconverters"," in 2010 First Power Quality Conferance, Sep. 2010, pp. 1-1.

[27] P. W. Wheeler, J. Rodriguez, J. C. Clare, L. Empringham, and A. Weinstein, "Matrix converters: a technology review," IEEE Transactions on Industrial Electronics, vol. 49, no. 2, pp. 276-288, April 2002.

[28] O. Ray and S. Mishra, "Boost-derived hybrid converter with simultaneous dc and ac outputs," IEEE Transactions on Industry Applications, vol. 50, no. 2, pp. 1082-1093, March 2014.

[29] M. Hannan, J. A. Ali, A. Mohamed, and A. Hussain, "Optimization techniques to enhance the performance of induction motor drives: A review," Renewable and Sustainable Energy Reviews, vol. 81, pp. 1611 - 1626, 2018. [Online]. Available: http://www.sciencedirect.com/science/article/pii/S1364032117308948

[30] H. Sathishkumar and S. Parthasarathy, "A novel neurofuzzy controller for vector controlled induction motor drive," Energy Procedia, vol. 138, pp. 698 - 703, 2017, 2017 International Conference on Alternative Energy in Developing Countries and Emerging Economies. [Online]. Available: http://www.sciencedirect.com/science/article/pii/S1876610217351469

[31] F. Zare and J. A. Firouzjaee, "Hysteresis band current control for a single phase z-source inverter with symmetrical and asymmetrical znetwork," in 2007 Power Conversion Conference - Nagoya, April 2007, pp. $143-148$.

[32] Zhangjie, Wupeng, and Hongjie, "Control strategy of microgrid inverter operation in grid-connected and grid-disconnected modes," in 2011 International Conference on Electric Information and Control Engineering, April 2011, pp. 1257-1260.

[33] Baolong Liu, Yabing Zha, Tao Zhang, and Shiming Chen, "Sliding mode control for rectifier stage of solid state transformer," in 2016 14th International Workshop on Variable Structure Systems (VSS), June 2016, pp. 286-289.

[34] F. Gavilán, S. Toledo, M. Rivera, D. Caballero, E. Maqueda, and R. Gregor, "Predictive current control strategy for a direct matrix converter with modulated switching pattern," in 2018 IEEE International Conference on Automation/XXIII Congress of the Chilean Association of Automatic Control (ICA-ACCA), Oct 2018, pp. 1-6.

[35] "Chapter 2 - uhv ac grid and system stability," in UHV Transmission Technology. Oxford: Academic Press, 2018, pp. 21 - 50. [Online]. Available: http://www.sciencedirect.com/science/article/pii/B9780128051931000021

[36] Z. Liu, "Chapter 7 - rd on global energy interconnection and practice," in Global Energy Interconnection, Z. Liu, Ed. Boston: Academic Press, 2015, pp. 273 - 342. [Online]. Available: http://www.sciencedirect.com/science/article/pii/B9780128044056000075

[37] K. Suganuma, "2 - interconnection technologies," in Wide Bandgap Power Semiconductor Packaging, ser. Woodhead Publishing Series in Electronic and Optical Materials, K. Suganuma, Ed. Woodhead Publishing, 2018, pp. 57 - 80. [Online]. Available: http://www.sciencedirect.com/science/article/pii/B9780081020944000025

[38] ABB, "Abb wins orders of over 300 million for world's first 1,100 kv uhvdc power link in china," abb.com, 072016.

[39] F. Schettler, H. Huang, and N. Christl, "Hvdc transmission systems using voltage sourced converters design and applications," in 2000 Power Engineering Society Summer Meeting (Cat. No.00CH37134), vol. 2, July 2000, pp. 715-720 vol. 2.

[40] Toshiba. HVDC enables long distance transmission and interconnection of asyncrous grids. (2019). [Online]. Available: https://www.toshibaenergy.com/en/transmission/product/power-conversion.htm 